Vol. 2, n. 3 - Edição Especial: Ciclos Formativos em Ensino de Ciências.

\title{
ESTRATÉGIAS FORMATIVAS NA FORMAÇÃO INICIAL E CONTINUADA DE PROFESSORES DE CIÊNCIAS
}

\author{
FORMATIVE STRATEGIES IN THE INICAL AND CONTINUING \\ FORMATION OF SCIENCE TEACHERS
}

\author{
Rosangela Inês Matos Uhmann (rosangela.uhmann@uffs.edu.br) \\ Universidade Federal da Fronteira Sul - UFFS
}

\begin{abstract}
Resumo: Este trabalho busca problematizar os diferentes momentos vivenciados pelos participantes dos Ciclos Formativos em Ensino de Ciências. O que nos convidou a fazermos uma reflexão sobre a prática pedagógica relacionada à organização do conhecimento relacionado ao ensino de Ciências da Natureza $(\mathrm{CN})$, momentos em que são trabalhados diferentes temas como da Educação Ambiental, avaliação, escrita e leitura, políticas públicas, ocasionando atualização curricular, bem como oficinas, atividades práticas entre outras, com foco na melhoria do ensino da área de $\mathrm{CN}$. Neste sentido, o envolvimento nos faz pensar no desenvolvimento das diferentes estratégias formativas em constante discussão nos ciclos, mostrando-se eficiente devido postura reflexiva dos participantes preocupados com o ensino da área de $\mathrm{CN}$, a exemplo da problematização das questões sociais e ambientais, visto a valorização da educação planetária e responsabilidade social, crítica e ecológica. Portanto, o caminho apontou para mais aprendizagens da realidade educacional e cultural do conhecimento devido avaliação dos saberes do ensino de Ciências, que se comunica entre si, com a vida e com o mundo.
\end{abstract}

Palavras-chave: Reflexão; Ciências; Problematização ambiental; Formação Docente.

Abstract: This work seeks to problematize the different moments experienced by the participants of the Science Education Formative Cycles. This invited us to reflect on the pedagogical practice related to the organization of knowledge related to the teaching of Natural Sciences $(\mathrm{CN})$, moments in which different topics such as Environmental Education, assessment, writing and reading, public policies are discussed, causing curriculum update, as well as workshops, practical activities, among others, focusing on improving teaching in the field of NC. In this sense, the involvement makes us think about the development of the different formative strategies in constant discussion in the cycles, proving to be efficient due to the reflective posture of the participants concerned with the teaching of the NC area, such as the problematization of social and environmental issues, 


\section{Vol. 2, n. 3 - Edição Especial: Ciclos Formativos em Ensino de Ciências.}

given the valorization of planetary education and social, critical and ecological responsibility. Therefore, the path pointed to more learning about the educational and cultural reality of knowledge due to the evaluation of the knowledge of science teaching, which communicates with each other, with life and with the world.

Keywords: Reflection; Sciences; Environmental Problematization; Teacher Training

\section{INTRODUÇÃO}

$\mathrm{Na}$ formação inicial e continuada proporcionada pelos Ciclos Formativos em Ensino de Ciências temos tido a oportunidade de dialogar junto aos professores das escolas, universidade e bolsistas dos diferentes Programas da Universidade Federal da Fronteira Sul (UFFS) a respeito das diferentes estratégias formativas envolvendo vários temas, além do envolvimento em discussões sobre as temáticas na apresentação de relatos de prática entre os participantes dos ciclos, bem como a publicação dos mesmos em eventos, e-book, periódicos, entre outros construídos no decorrer do processo formativo nos ciclos. De forma que cada relato construído e apresentado nestes sistemáticos anos de formação dos ciclos tem feito a diferença na vida dos estudantes, assim como na atuação do próprio professor da área de Ciências da Natureza (CN).

Diríamos que o desafio esteve sempre voltado para atingir o máximo possível de envolvidos no processo das discussões e escrita, ou seja, é fato que a valorização pelo diálogo sempre foi constante visto as diferentes necessidades e potencialidades externadas primando sem sombra de dúvida pela melhoria da própria prática educativa. O que elevou o potencial das reflexões e discussões compartilhadas na construção de cada relato de prática.

Neste sentido, o que nos fez pensar e desenvolver diferentes estratégias formativas respectivo aos diferentes temas como da Educação Ambiental (EA), avaliação educacional, leitura e escrita, Políticas Públicas, documentos como a Base Nacional Curricular Comum (BNCC) entre outros por meio de encontros formativos estão sendo essenciais ao processo formativo, devido ao imbricado movimento da investigação-ação. 


\section{Vol. 2, n. 3 - Edição Especial: Ciclos Formativos em Ensino de Ciências.}

Nesse panorama: "[...] o processo de criar as condições em que os protagonistas podem estabelecer um programa de reflexão crítica para organização da ação colaborativa com vistas à reforma educativa" (CARR; KEMMIS, 1988, p.198, [tradução própria]) favorece a reflexão individual e coletiva.

Uma das formas é justamente a formação inicial e continuada permeada pelo movimento da investigação-ação que vem aproximando o trabalho docente dos professores (das escolas e universidade), com os licenciandos em formação inicial no diálogo e discussão crítica de forma colaborativa e formativa. Vale destacar que a formação vivenciada nos ciclos se torna constitutiva da prática docente, permitindo ao professor, que participa ativamente, reavaliar, repensar e reconstruir suas práticas pedagógicas e assim vai beneficiando os estudantes, bem como, os pares com os quais interage diariamente nas escolas.

Enfim, cada participante dos ciclos torna-se um mediador qualificado das ações e das práticas, pois o processo de reflexão e de discussão crítica repercute nas atividades de ensino e no diálogo com seus pares melhorando a prática docente dos envolvidos nos ciclos, bem como dos licenciandos que são beneficiados na interação dialógica desde a formação inicial.

\section{DETALHAMENTO DAS ATIVIDADES}

Os encontros mensais dos Ciclos Formativos em Ensino de Ciências (vinculado a um Projeto de Extensão), vem ocorrendo desde 2009 desenvolvido junto aos professores das escolas, universidade e Licenciandos da UFFS. Momentos que se tornou um ambiente de compartilhamento das vivências de sala de aula, bem como a discussão das diferentes formas de mediar o conhecimento no desenvolvimento dos conteúdos da área de $\mathrm{CN}$. Os participantes são professores de Ciências, Biologia, Física e Química, área CN, assim como os professores da UFFS que atuam na Licenciatura dos Cursos de Ciências Biológicas, Física e Química Licenciatura, bem como os licenciandos vinculados ao 


\section{Vol. 2, n. 3 - Edição Especial: Ciclos Formativos em Ensino de Ciências.}

Programa de Iniciação à Docência (PIBID), Programa de Educação Tutorial (PET), Residência Pedagógica (RP) e demais bolsistas de pesquisa e extensão da UFFS, Campus Cerro Largo. Tais participantes, além da escrita de relatos como este, também fazem uso do Diário de Bordo (DB), os quais são desafiados a escreverem mensalmente respectivo ao processo formativo, tendo em vista a própria prática docente e/ou discussões críticas sobre as diferentes temas (EA, avaliação educacional, leitura e escrita entre outros) programados para os encontros dos ciclos.

O instrumento do DB é muito importante para a formação inicial e continuada de professores constituindo um "[...] guia para reflexão sobre a prática, favorecendo a tomada de consciência do professor sobre seu processo de evolução e sobre seus modelos de referência" (PORLÁN; MARTÍN, 1997, p.19-20). A escrita reflexiva sobre a prática docente é muito importante para a formação do professor, pois a escrita ajuda na reflexão da atividade realizada e/ou a ser realizada pelos futuros professores da área de $\mathrm{CN}$.

\section{DISCUSSÃO DO RELATO}

Atualmente na formação de professores faz-se necessário a inserção dos mesmos em projetos de extensão no sentido de fazer a ponte entre a formação e a atuação, visto o conhecimento da realidade escolar. O que exige preparação e conhecimento do que poderá ser encontrado e ainda, a questão da instabilidade, da diferença, da complexidade, da exigência, do conhecimento poderoso, entre os aspectos imprevistos. No entanto, o planejamento, a ação, avaliação, reflexão, por exemplo, precisam estar impregnados em cada espaço-tempo escolar com atenção ao rompimento das fronteiras disciplinares.

É neste sentido, que se exige aumentar a relação universidade e escola na necessária articulação junto aos processos de formação e planejamento das ações de ensino, junto ao programa e escolas, tendo em vista a melhoria com excelência das práticas didático-pedagógicas escolares para a educação brasileira. Outra questão diz respeito aos anseios dos professores que precisam ser levados em conta, o que favorece a socialização e compartilhamento das práticas possibilitando reflexões sobre e para a 


\section{Vol. 2, n. 3 - Edição Especial: Ciclos Formativos em Ensino de Ciências.}

prática junto aos licenciandos e formadores, bem como em ações e Programas do PET, PIBID e RP, de extensão e de pesquisa no fortalecimento dos cursos de Licenciatura da UFFS.

A troca de experiência fortalece a organização de ações conjuntas de formação atingindo todos os sujeitos envolvidos tanto na formação inicial quanto na continuada. Por isso, uma das formas promissoras de pensar a função educativa na escola diz respeito a induzir ações concretas que possibilitem a formação de atitudes e valores, articuladamente ao desenvolvimento do currículo escolar. Neste sentido, os temas como da EA, avaliação, escrita e leitura, TICS, bem como das oficinas dentre outras propostas de estratégias formativas da área de CN intencionou desenvolver uma investigação crítica da realidade local/global, além da conscientização para a preservação dos recursos naturais, redução do consumo induzido, escolha adequada dos alimentos, redução do uso da energia elétrica e atitudes para melhorar as formas de ensinar e aprender em Ciências. Na perspectiva de contribuir para a melhoria da qualidade da educação e da vida, frente à visão de um futuro a partir do que é possível fazer e mudar atualmente.

De forma complexa em todos os aspectos, do curricular, disciplinar ao didáticopedagógico acompanhado de uma abordagem interdisciplinar relacionada à contextualização no estabelecimento das necessárias relações levando em consideração o disciplinar. O que exige uma formação que ultrapasse as paredes da universidade e da escola, vista a complexidade sobre o aprender e ensinar Ciências, por exemplo, na contemporaneidade, necessitando de reflexão desde a formação inicial, em que apostamos na investigação-ação imbricada na estrutura de diálogo entre professor de escola, formador e licenciando. Enfim, a formação nos ciclos vem contribuindo não só para o professor efetivo, mas talvez, e principalmente, para o professor em formação inicial.

Reforçamos através da análise cotidiana em sala de aula que é possível construir conhecimentos significativos ao perpassar também por questões socioambientais, avaliativas, de instigação da leitura e da escrita reflexiva, por exemplo sobre a própria prática, além da base complementar entre aquilo que se sabe, que se planejou, com aquilo 


\section{Vol. 2, n. 3 - Edição Especial: Ciclos Formativos em Ensino de Ciências.}

que é feito na interação com os estudantes. Com isso não se quer dizer que há uma mera transposição de fatos ou modos de pensar e agir, mas uma valorização de um movimento dinâmico de ação/reflexão/ação sobre as práticas, um movimento, sobretudo, no sentido de querer aprender e de querer ensinar em consonância com o que se aprendeu.

Como refere Schön (1992), o modo de operar no meio educacional implica lidar com situações complexas, com o incerto, o imprevisível, o inesperado. Nas palavras de Morin: "[...] a complexidade é um problema, é um desafio e não uma resposta" (2002, p.559). O professor vive a prática docente diariamente permeado pela sua formação, e também, ao longo da formação continuada, tendo acesso aos conhecimentos produzidos histórica e socialmente, sendo seu próprio motor de partida e chegada. Para tanto, os ciclos vivenciados na coletividade e interação proporciona estudos e reflexões em espaços organizados, planejados, acompanhados e avaliados construtivamente entre os participantes, fazendo a ponte entre os saberes na complementaridade, intencionalidades e as práticas educativas.

Na complexidade e multiplicidade das ações educacionais, interações, indagações e comunicações que os educadores definem as dinâmicas das aulas, decidem e conduzem as atividades em determinado espaço e tempo da vida escolar. Possivelmente, é a partir da prática docente que o professor tem a oportunidade de lidar com os diversos temas, quando passa a se perguntar: de que maneira as teorias e práticas perpassam a prática cotidiana educacional? Como explicitar e explicar um trabalho docente realizado por meio da escrita de um relato de prática? Como o espaço em sala de aula possibilita a articulação entre o trabalho diário da sala de aula na construção do conhecimento escolar por meio da EA, por exemplo? É possível identificar e compreender relações entre a prática pedagógica escolar e o dia a dia dos estudantes? Que interesses e princípios sustentam a vinda dos estudantes na escola? Enfim, são questões voltadas à complexidade funcional de uma sala de aula, muitas vezes superiores àquelas consideradas pelas teorias e/ou discursos sobre ensino da área de $\mathrm{CN}$, no qual se exige entender os conceitos escolares articuladamente aos problemas sociais e ambientais, principalmente e, com uma 


\section{Vol. 2, n. 3 - Edição Especial: Ciclos Formativos em Ensino de Ciências.}

linguagem científica. Sendo que: "Aprender ciências é apropriar-se do discurso da ciência, ter condições de se expressar em sua linguagem, empregando adequadamente os conceitos científicos" (MORAES, 2006, p. 30).

É da escola, instituição formadora, que se cobram responsabilidades com a qualidade do ambiente, da avaliação, do escrever, ler, ensinar e aprender que precisam também das relações sociais, culturais e ambientais de fundamental importância ao ensino de Ciências, bem como para preservação da vida. É na escola que as ações começam a ser questionadas, no qual muitos fatores podem contribuir nas relações em sala de aula, mas o mais importante é levar em conta a intervenção do conhecimento que acontece mediante as interações e inter-relações na escola, frente ao papel do outro no desenvolvimento da aprendizagem. Com base em Vigotski, Marta Kohl Oliveira (1997, p.58) esclarece:

Essa concepção de que é o aprendizado que possibilita o despertar de processos internos do indivíduo liga o desenvolvimento da pessoa a sua relação com o ambiente sócio-cultural em que vive e a sua situação de organismo que não se desenvolve plenamente sem o suporte de outros indivíduos de sua espécie.

O trabalho docente e discente acontece na mediação entre os sujeitos escolares referentes aos objetos de estudo, jamais de forma isolada. Nesse sentido, a riqueza do trabalho desenvolvido no âmbito dos ciclos por meio da investigação-ação está sendo possível devido à relação com os diversos conceitos problematizados e tematizados no contexto formativo mediado entre os participantes na perspectiva de proporcionar o desenvolvimento do pensamento, das questões socioambientais, da dialogicidade, dentre outros na argumentação ativa e autônoma entre os professores em formação inicial e continuada da área de $\mathrm{CN}$.

\section{CONCLUSÃO}




\section{Vol. 2, n. 3 - Edição Especial: Ciclos Formativos em Ensino de Ciências.}

É fato que os Ciclos Formativos em Ensino de Ciências tem ocasionado mudanças na realidade escolar pelos professores, o que é demonstrado no discurso dos mesmos, visto as concepções externadas sobre o processo de ensino e aprendizagem. Outra caracterização é a emergência de temas contemporâneas, tecnológicas e transversais envolvidos com intensa discussão no respectivo encontro dos ciclos, sendo possível devido formação continuada imbricada entre os professores das escolas, formadores e licenciados.

Além disso, o professor em formação continuada passa a participar de eventos, inclusive escrevendo relatos de suas práticas. Nisso, mais ações são incentivadas como as oficinas da área de $\mathrm{CN}$, cinema, EA na perspectiva crítica entre outras que vão sendo propostas, pois vão emergindo dos encontros dos ciclos por necessidade, e assim vai se consolidando a formação de professores de formação inicial e continuada com excelência.

\section{REFERÊNCIAS}

MORAES, Roque, et al. Pesquisa em sala de aula: fundamentos e pressupostos. In: MORAES, Roque, MANCUSO, Ronaldo. Educação em Ciências: produção de currículos e formação de professores. Ijuí: Unijuí, 2006.

MORIN, Edgar. A Religação dos Saberes, o desafio do século XXI. Rio de Janeiro: Bertrand Brasil, 2002.

OLIVEIRA, Marta Kohl. Aprendizado e desenvolvimento: um processo sócio-histórico. São Paulo: Scipione, 1997.

SHÖN, Donald A. Formar Professores como Profissionais Reflexivos. In: NÓVOA, A. Formação do profissional reflexivo. Lisboa: Dom Quixote, 1992.

VIGOTSKI, L.S. A Formação social da mente. São Paulo: Martins Fontes, 2008. 